\title{
So muss Lithium! (nicht)
}

\section{Enrico Danieli}

Dr. med., Facharzt für Allgemeine Innere Medizin, Mitglied FMH

Möglich, dass ich ein wenig zittrig war, zerfahren, unsicher - die Behandelnden meinten, ein Lithiumspiegel müsse her. Natürlich, sagte ich. Überall könnte ich ihn bestimmen lassen, das sei gar kein Problem. Beim Verlassen der Praxis wusste ich, was ich zu tun hatte. Doch wohin? An wen mich wenden? Ich hatte keinen Arzt meines Vertrauens. Dies betreffend war ich flottierend; immer wieder scheiterte ich am Gefühl, nicht wahrgenommen zu werden, da meine Klagen ohne Bedeutung waren, reflexartig wurde auf die Grundkrankheit hingewiesen: Ursache und Folge in einem. Ich hatte gedacht, eine Teampraxis wäre das Einfachste, um so bald als möglich einen Spiegel zu haben. Hier, in einem Haufen Mediziner, musste mit Bestimmtheit jemand ein wenig Zeit haben. Da, wohin ich ging, gab es einen Warteschlauch mit 20 Stühlen, alle besetzt, einige Patienten, Patientinnen warteten stehend, im rechten Winkel der Empfang mit jeweils vier Assistentinnen in Eile zwischen Telefon und verschiedenen Praxisräumen. Es war heiss, stickig, ich sah kein Fenster, der Geruch schwer. Neue Patienten kamen, wurden registriert, suchten den Warteschlauch auf, andere gingen. Links ein langer Gang und Türe an Türe, fünf pro Seite, der Ärztetrakt. Ich verstand nun, weshalb vor dem Praxiseingang das Schild mit den Ärzten, die hier arbeiteten, ohne Ende war, Name unter Name, Spezialausbildungen, unverständliche Abkürzungen. Die Türen im Ärztetrakt blieben verschlossen, einmal kam einer und verschwand in der nächsten Türe, ohne wieder zu erscheinen. Patienten waren nur kurz zu sehen. Jetzt, nach langem Warten, war ich an der Reihe. Eine junge Anmeldeassistentin mit rasiertem Kopf und roten Stoppeln. Mein Lithiumwunsch löste Heiterkeit aus, auch mein «Noch-nie-dagewesen». Sie hätten den Lithiumtag am Freitag, nicht heute Dienstag. Bei Neuanmeldungen sei mit Wartezeiten zu rechnen. Ob ich ein Überweisungsschreiben eines Psychiaters hätte. Alles so laut, so drohend, ich spürte viele Blicke in meinem Rücken. Wenn ich kein Zuweisungsschreiben hätte, dann müsste vor der Blutentnahme einer ihrer Ärzte ein Gespräch mit mir führen, um festzustellen, ob die Indikation für eine Lithiumbestimmung auch gegeben sei - um Kosten zu sparen. Schweiss bedeckte meinen Körper, ich musste mich an der Theke festhalten, ich kam mir vor wie in einem Hinterhalt, zum Abschuss freigegeben. Zuerst müsste ich, zusammen mit der Krankenkassenkarte, meine per- sönlichen Koordinaten angeben, so könnten sie mich bestellen, wenn sie eine freie Nische hätten. Wollte ich das überhaupt? Doch was sollte ich tun? Die Karte wurde fotokopiert, meine Daten abgefragt. Bei «Beruf) zögerte ich. Das sei wichtig, wurde ich belehrt, sie könnten nur Patienten behandeln, von denen alle Eckdaten bekannt seien - ich fand keinen Ausweg, sagte leise: «Krankheit.» Es folgte lautes Lachen, welche Krankheit ich denn hätte. Mein junges Gegenüber meinte wissend und überlegen, dass Lithium ja schon alles sage. Ich schaute in Richtung Warteraum, und tatsächlich, alle Augen waren auf mich gerichtet. Dabei hatte ich doch nichts getan. Hinter mir, laut atmend, ein jüngerer Arzt im offenen weissen Mantel und in schwarzer Hose, schwarzem Hemd, das Stethoskop um den Hals gebunden, auch er schaute mich von der Seite an, unterbrach das Gespräch, um Akten von diesem und jenem Fall, wie er sich ausdrückte, zu verlangen. Dies dauerte, die Akten mussten gesucht werden. Daneben lief alles weiter, die einen kamen, andere gingen, und alle mit einem ähnlichen Text versehen, auswechselbar: nächster Termin/vorher pieksen/nachher pieksen / sicher nüchtern/sicher nicht nüchtern / Vorbesprechung/Nachbesprechung. Als man Zeit hatte, wurde mir mitgeteilt, dass die für die Psychiatrischen vorgesehene Jungärztin (?) sich noch 6 Wochen im Babyurlaub befinde und dass ihre Stellvertretung sich diese Woche in einem Fortbildungsseminar weiterbilde, weshalb einen Termin nächste Woche zu fixieren unmöglich sei, denn sie seien pumpenvoll. Ich schwieg, meine Felle schwammen davon. Im Klartext: Man will mich nicht, ohne Zweifel lithiumbedingt. Ob ich nüchtern sei, wollte die junge Frau wissen. Nüchtern, es war mitten am Vormittag. Lithium würden sie nur nüchtern abnehmen, Lithium dürfe man nicht einnehmen. Ach, fügte sie hinzu, es fehle auf dem Koordinatenblatt meine Krankheit. Ich schwieg, ich schwieg beharrlich. Ich konnte nichts mehr sagen. Nicht so öffentlich, vor diesen vielen Leuten, vor dem Arzt mit dem Stethoskop, der mich bereits als Aussätzigen diagnostiziert hatte. Ich ging zur Türe, ich rannte weg, wie jemand rennt, der der Hölle entflohen ist. Mein Lithium pendelt, unbestimmbar geworden, weiter durch mein Blut. (Und die Daten? Die sind, stelle ich mir vor, verloren, nein: Sie pendeln auf ewig im All - immerhin ohne Diagnose: mein letzter Triumph ...) 